\title{
PRECIPITATION AND ENCAPSULATION OF ROSEMARY ANTIOXIDANTS BY SUPERCRITICAL
}

\section{ANTISOLVENT PROCESS}

\author{
A. Visentin ${ }^{1,2}$, S. Rodríguez-Rojo ${ }^{1 *}$, A. Navarrete ${ }^{1}$, D. Maestri ${ }^{3}$, M. J. Cocero ${ }^{1}$
}

(1) Universidad de Valladolid. Escuela de Ingenierías Industriales - Sede Dr. Mergelinac/ Doctor Mergelina s/n 47011 Valladolid, España

(2) Universidad de Río Cuarto. Ruta Nac. 36 - Km. 601, Río Cuarto, Córdoba, Argentina

(3) Facultad de Ciencias Exactas, Físicas y Naturales. Universidad Nacional de Córdoba - Conicet. Av. Vélez Sarsfield 1611 - Ciudad Universitaria. X5016GCA Córdoba, Argentina.

\section{Abstract}

The encapsulation of antioxidants with biocompatible polymers is essential for their protection against degradation factors like light and oxygen, and facilitates its solubility in the target medium. This work presents the co-precipitation of an ethanolic extract of rosemary leaves by supercritical antisolvent (SAS) process in poloxamers in order to improve the aqueous solubility of the extract. In a first step, the precipitation of antioxidants by SAS was studied in the range of temperatures from 25 to $50^{\circ} \mathrm{C}$ and pressures from 8 to $12 \mathrm{MPa}$. Total content of polyphenols was quantified according to the Folin-Cicalteu method. Also HPLC analyses were performed to verify the presence of some of the major rosemary antioxidants, carnosic and rosmarinic acid. The dissolution rate of rosemary polyphenols from particles was measured in isotonic phosphate buffer solution $(\mathrm{pH}=6.8)$. The encapsulation of the extract was successfully achieved with a yield up to $100 \%$. The total polyphenolic content was dissolved from the encapsulated product, in the aqueous medium, after one hour, whereas only $15 \%$ of the antioxidants of the pure precipitate were dissolved after 8 hours.

\section{Keywords}

Antioxidants, Rosemary, Poloxamer, encapsulation, supercritical antisolvent (SAS) 


\section{Introduction}

Rosemary (Rosmarinus officinalis) plant species has been largely studied as a source of natural products with diverse biological activities. Rosemary leaves and leaf extracts are increasingly used as food and cosmetic preservatives thanks to their content in antioxidant compounds as substitutes of synthetic antioxidants as butylated hydroxyanisole (BHA) and butylated hydroxytoluene (BHT) (Etter, 2005). Moreover, rosemary antioxidants are emerging as prophylactic and therapeutic agents. They have showed antimicrobial, anti-inflammatory, antitumorigenic and chemopreventive activities which make them suitable candidates as bioactive ingredients to design functional foods (Ratnam et al., 2006; Soler-Rivas et al., 2010).

Commonly herbal extracts are marketed in the form of liquid, viscous preparations and also as powders resulting from the drying of a liquid extract. The advantages of the dried extract over conventional liquid forms are lower storage costs and higher concentration and stability of active substances (Souza et al., 2008). Additionally, and for any application, the solubility characteristics of the antioxidant in relation to the site of action must also be considered: as food preservatives, watersoluble antioxidants are very effective in muscle foods (e.g. meat) where many oxidative reactions occur in the aqueous environment, while water soluble fractions are ineffective in lipid emulsions where oxidation occurs in the lipid phase or at the lipid interface (Decker, 1998). As ingredients in functional foods, rosemary antioxidants have to be bioavailable. However, oral delivery of these antioxidants is a challenge due to various reasons such as poor solubility, instability and extensive digestion before reaching systemic circulation (Ratnam et al., 2006; Soler-Rivas et al., 2010). In view of the above-mentioned drawbacks, encapsulation with an appropriate carrier material is necessary to obtain an effective product. Besides, encapsulated polyphenols will be protected during manufacturing processes and its palatability will be improved. (Kosaraju et al., 2008).

In this work, poloxamers were selected as encapsulating compounds. Poloxamers are triblock copolymers, type A-B-A, consisting of ethylene oxide (A: EO) and propylene oxide (B: $P O)$ monomers 
in an arrangement that allows the formation of self-assembled micelle structures in aqueous media, based on the relative difference in hydrophobicity between PO and EO (the cores of PO and water are surrounded by coronas consisting of EO and water). Therefore, they can improve the bioavailability of lipophilic compounds in aqueous media (Sharma et al., 2008; Majerik et al, 2007). Additionally, they have generated much interest in the field of drug controlled release due to their ability to form gels in response to changes in temperature (Escobar-Chávez et al., 2006).

Recently, many ways to produce particles containing active components by using different polymers have been studied. Supercritical carbon dioxide $\left(\mathrm{SC} \mathrm{CO}_{2}\right)$, in particular, is an advantageous processing medium for particle encapsulation because of its relatively mild critical conditions (Tc 304.1 K, Pc 7.38 MPa). Furthermore, $\mathrm{SC} \mathrm{CO}_{2}$ is nontoxic, nonflammable, relatively inexpensive, readily available and chemically stable.

One of the most versatile processes for particle formation with supercritical carbon dioxide is the supercritical anti solvent process (SAS), where the solute of interest is first dissolved in a conventional solvent and the solution is sprayed continuously through a nozzle, co-currently with the $\mathrm{SC} \mathrm{CO}$ into a chamber at moderate pressure and temperature. The high pressure $\mathrm{CO}_{2}$ acts as an antisolvent, decreasing the solubilities of the solutes in the mixture. Therefore, a fast supersaturation takes place, leading to nucleation and formation of nano- or micro-particles. It is also possible to produce polymer co-precipitates or microcapsules in a single step using a polymer soluble in the same extract as the active compound (Cocero et al., 2009; Mattea et al., 2009).

SAS process has been already applied to the precipitation of green tea polyphenols (Mertec, et al., 2009) and to its encapsulation in polycaprolactone (Sosa et al., 2011).

A specific literature survey on the drying and encapsulation process of rosemary liquid extracts shows that research is limited, and is mainly focused on the isolation of carnosic acid (CA), one of the main antioxidant compounds in rosemary. Bailey and co-workers (1999) patented a pH controlled precipitation process for rosemary antioxidants which generates a product with mass concentration of CA between 50 to $65 \%$. The extraction of the antioxidants with acetone, a water- 
miscible solvent, is followed by an increment of $\mathrm{pH}$ up to a value around 9 in order to form a salt of CA (sodium or ammonia salt). Afterwards, between four to nine volumes of buffer at the same $\mathrm{pH}$ are added to precipitate impurities while the salt of CA remains in solution. This solution is partially evaporated in vacuum to eliminate the organic solvent and volatile compounds, responsible for the spice odor and taste, with the steam. Then the $\mathrm{pH}$ is reduced to a value between 2 to 3 with phosphoric acid or acetic acid to obtain a precipitate with a high content of $C A$, which is recovered from the aqueous solution by filtration and finally dried at vacuum. Although this process provides a good yield of CA, it entails many purification steps, high energy consumption (evaporation and vacuum) and the use of high amount of water.

Rodríguez-Meizoso et al., 2008 presented preliminary results in precipitation of rosemary antioxidants by RESS, rapid expansion of supercritical solution, process. Firstly, the extraction of rosemary antioxidants with $\mathrm{CO}_{2}$ using ethanol as co-solvent was performed at $15 \mathrm{MPa}$ and $40{ }^{\circ} \mathrm{C}$. Afterwards, this solution was expanded to atmospheric pressure in a chamber at 50 ㅇ $\mathrm{C}$ to favor the evaporation of the solvent and avoid re-dissolution of the antioxidants in the ethanol. The analysis of the particles revealed a $4 \mathrm{wt} . \%$ content of CA. However, the yield was not reported although considering the extraction conditions and solubility studies (Cháfer et al., 2005) it should be low. Moreover, the possibility of coupling the precipitation and encapsulation process is unlikely since few polymers are soluble in $\mathrm{SC}^{-} \mathrm{CO}_{2}$ (Cocero et al., 2009).

$$
\text { More recently, Visentin et al. (2011) developed a two-stage fractionation process from a high }
$$
viscous ethanolic oleoresin based on the solvent and antisolvent power of $\mathrm{SC}_{-}-\mathrm{CO}_{2}$. As a result, two fractions were obtained; the first one was a dark green powder, insoluble at $30 \mathrm{MPa}$ and $50^{\circ} \mathrm{C}$ with low concentration of CA ( $<5 \mathrm{~g} / 100 \mathrm{~g}$ extract). The other fraction, an orange colored resinous extract with a high concentration of CA (33 wt.\%), was precipitated at $10 \mathrm{MPa}$ and $50^{\circ} \mathrm{C}$.

Regarding the encapsulation, Souza et al., 2008 dried ethanol: water (70:30) extracts by spray drying and spouted bed dryer. They used a mixture of silicone dioxide and maltodextrine, as watersoluble carrier material, in a ratio of 2:1 with respect to the solid content of the rosemary extract. 
However, the degradation of the phenolic compounds was quite high (ca. $50 \%$ ) probably due to the high temperatures of the process $\left(150^{\circ} \mathrm{C}\right)$.

The aim of this work is the study of antioxidants precipitation from ethanolic rosemary extracts by Supercritical Antisolvent Process (SAS) at mild temperatures. The encapsulation with polymers using the same process to protect the antioxidants and to improve its aqueous solubility is also evaluated.

\section{Materials and Methods}

\subsection{Materials}

Rosemary was collected in April and June 2010, in Peñafiel (Valladolid, Spain). Plants were stored at $4^{\circ} \mathrm{C}$ until needed for the extractions. For every experiment only the leaves were used, which were removed from the stems.

Ethanol of $96 \%$ purity, Folin-Ciocalteu reagent, gallic acid and sodium carbonate were purchased from Panreac Química (Spain). The polymers, Pluronic ${ }^{\circledR} \mathrm{F} 88$ (Poloxamer 238; HLB >24; $T_{m}$ $=54^{\circ} \mathrm{C}$ ) and Pluronic ${ }^{\oplus} \mathrm{F} 127$ (Poloxamer 407; $\mathrm{HLB}=18-23 ; \mathrm{T}_{\mathrm{m}}=57.6^{\circ} \mathrm{C}$ ), were a gift from BASF. All products were used as received. Cromatographic standards, rosmarinic acid and carnosic acid, were purchased from Sigma-Aldrich. Acetonitrile, acetic acid and methanol (all HPLC gradient grade) were purchased from Panreac Quimica (Spain). Water was Milli-Q quality. These solvents were degassed and filtered through a $0.22 \mu \mathrm{m}$ membrane (Fluoropore ${ }^{\mathrm{TM}}$, Millipore) before their utilization.

\subsection{Methods}

\subsubsection{Preparation of Rosemary ethanolic extracts and polymer solutions}

Extraction was performed according to a previous work (Navarrete et al., 2011). First, the leaves were de-oiled by solvent free microwave extraction (SFME): rosemary leaves ( $50 \mathrm{~g})$ were put into a microwave apparatus and subjected to $450 \mathrm{~W}$ for $5 \mathrm{~min}$. Secondly, $200 \mathrm{~mL}$ (96\%) of ethanol preheated at $40^{\circ} \mathrm{C}$ were added (ratio $4: 1 \mathrm{v} / \mathrm{w}$ ) and the mixture was stirred by rotation at $55 \mathrm{rpm}$. After 4 hours, the extract was filtered (MF-Millipore ${ }^{\mathrm{TM}}$, pore size $0.45 \mu \mathrm{m}$ ) by vacuum at $20 \mathrm{mbar}$, the liquid phase was recovered and stored at $4-6^{\circ} \mathrm{C}$, before use. 

material (Navarrete et al., 2011; Rodriguez-Rojo et al., 2011). Besides, essential oil monoterpenes, such as camphor or 1,8-cineole, responsible for the specific taste and odor of the spice, are eliminated since universally accepted antioxidants should be odorless, flavorless and colorless (Bailey et al., 1999).

For the co-precipitation experiments, the polymer, either Pluronic ${ }^{\circledR}$ F88 or Pluronic ${ }^{\circledR}$ F127,

was dissolved in the extract in a mass ratio with respect to the dry content of the extract of 2.5:1.

\subsubsection{SAS (Supercritical Anti Solvent): Precipitation and co-precipitation experiments}

shown in Fig. 1. The $\mathrm{CO}_{2}$ used is cooled down before being pressurized with a diaphragm pump

flow is measured with a coriolis flow meter. When the mass flow of $\mathrm{CO}_{2}$ is constant and the working pressure and temperature remain stable, the solution is pumped by a chromatographic pump (Jasco PU 2080 - Plus) into the precipitator at the desired flow rate. This precipitator is equipped with a Pt -100 thermoresistance with an accuracy of $\pm 0.1 \mathrm{~K}$ and a membrane digital pressure meter with an accuracy of \pm 0.25 bar to measure operating conditions. The inlet of the fluids is made through a concentric tube nozzle placed at the center top of the precipitation vessel; the nozzle consists of a 1/16 in. tube (inner diameter: $1 \mathrm{~mm}$ ) for the solution, placed inside a $1 / 4$ in. tube $\left(3.2 \mathrm{~mm}\right.$ i.d.) for the $\mathrm{CO}_{2}$. At the bottom of the vessel there is a porous metallic frit with a screen size of $1 \mu \mathrm{m}$. There is also an external stainless steel filter, which has a screen size of $1 \mu \mathrm{m}$. plugging. A vessel is used to achieve the separation of solvent and $\mathrm{CO}_{2}$ after pressure release. 

and only pure $\mathrm{CO}_{2}$ is fed for 10 minutes at a four times higher flow rate and the same operating conditions to ensure the complete removal of organic solvent from the precipitator. Finally, the precipitator is depressurized and the particles are recovered $(10-1000 \mathrm{mg})$. The precipitate is stored under nitrogen atmosphere, protected from light and at temperatures below $5^{\circ} \mathrm{C}$, to avoid the decomposition of the product, before their analysis.

\subsubsection{Product analysis}

The precipitation yield was determined by weighing the total amount of particles collected in the precipitator related to the total amount of soluble solids in the original solution.

The total soluble material concentration of the extracts was determined by drying $25 \mathrm{~mL}$ of extract under vacuum at $40^{\circ} \mathrm{C}$ on a rotatory evaporator. The mean experimental uncertainty was $5 \%$.

As the yield of the precipitation was determined by comparison with this value, its mean uncertainty was also $5 \%$. The dried extract was analyzed for total polyphenol, carnosic and rosmarinic acids content, as well, as reference for the SAS procedure. et al., 1999) using gallic acid as reference compound; hence, total phenolics were determined as gallic acid equivalents (GAE). Samples were prepared by dissolution of ca. $10 \mathrm{mg}$ of powder in $2 \mathrm{~mL}$ of ethanol for pure extract powder, or ca. $40 \mathrm{mg}$ of encapsulated product in $2 \mathrm{~mL}$ ethanol. The analysis was carried out in triplicate and compared to the maximum loading achievable considering the initial amount of total polyphenols in the feed, pure rosemary extract or the solution of the polymer in the extract.

Additionally, major components of the rosemary extract (rosmarinic and carnosic acid) were determined by high performance liquid chromatography (HPLC) according to the method of

178 (Wellwood \& Cole, 2004) adapted from Cuvelier et al., (1996). It was performed on a reversed phase 179 C18 Hypersil- ODS column ( $25 \mathrm{~cm} \times 4.6 \mathrm{~mm}, 5 \mu \mathrm{m}$ pore size; Supelco). The sample volume of injection was $20 \mu \mathrm{L}$; liquid samples were injected directly and for the solid samples, $20 \mathrm{mg}$ of the product was 
dissolved in $0.5 \mathrm{~mL}$ of ethanol. The mobile phase was programmed with a linear gradient elution method from $90 \%$ A ( $840 \mathrm{~mL}$ of deionized water with $8.5 \mathrm{~mL}$ of acetic acid and $150 \mathrm{~mL}$ of acetonitrile), $10 \% \mathrm{~B}$ (methanol), to $100 \% \mathrm{~B}$ in $30 \mathrm{~min}$, with a flow rate of $1.5 \mathrm{~mL} / \mathrm{min}$. The system was left to stabilize for $3 \mathrm{~min}$ between consecutive injections. The column temperature was $25^{\circ} \mathrm{C}$. The samples were detected by UV at $284 \mathrm{~nm}$. The compounds were identified by comparison with the relative retention time of standards in ethanol, calibrated between 0.2 and $20 \mathrm{mg} / \mathrm{mL}$, and with reference to a published chromatogram (Cuvelier et al., 1996). Before HPLC analysis, the samples were filtered through a $0.2 \mu \mathrm{m}$ nylon membrane filter (Millex GN from Millipore). The maximum uncertainty of the analysis is $4 \%$. The presented values are the mean of three independent experiments of precipitation, to test reproducibility, and the mean error amounts to $20 \%$. For particle characterization of the collected precipitates scanning electron microscopy (SEM) micrographs were taken by means of a scanning electron microscope model JEOL JSM-820. Particles of representative samples were gold sputtered in an argon atmosphere at room temperature before examination.

Differential scanning calorimetry (DSC) assays of pure and encapsulated extract samples were carried out with a DSC-30 METTLER apparatus. Analyses were performed from -50 to $250^{\circ} \mathrm{C}$, at a heating rate of $10^{\circ} \mathrm{C} / \mathrm{min}$ and $60 \mathrm{~mL} \mathrm{~N} / \mathrm{min}$.

\subsection{Dissolution Test}

The dissolution rate of the antioxidants from the extract precipitate and its polymer coformulations in isotonic phosphate buffer pH 6.8 was measured. Additionally, physical mixtures of the polymer and the extract in the same ratio have been also tested to investigate whether the effect of the polymer on the dissolution rate is due just to its nature as surfactant or to interactions between the polymer and the compounds of the rosemary extract formed during the coprecipitation process. Samples of powder (ca. $200 \mathrm{mg}$ ) were placed in $25 \mathrm{~mL}$ of solution at $37^{\circ} \mathrm{C}$. The mixture was stirred at $100 \mathrm{rpm}$ for 8 hours and $2 \mathrm{~mL}$ aliquots were taken at pre-defined intervals. The sample volume was replaced with fresh buffer solution. The aliquot was filtered through a 
membrane filter ( $0.2 \mu \mathrm{m}$, Millex GN from Millipore) and the filtrate was analyzed directly by FolinCicocalteu method to quantify the total amount of polyphenols. The presented values are the mean of two independent experiments of dissolution and are expressed in terms of \% dissolved polyphenols, that means, the actual polyphenol concentration in the solution divided by the polyphenol loading of the particles (determined as in section 2.3.3) and multiplied by 100 .

\section{Results}

\subsection{SAS Precipitation}

The influence of the main variables of the supercritical antisolvent process, pressure and temperature, was studied in the range from $8-12 \mathrm{MPa}$ and $25-50^{\circ} \mathrm{C}$. Other operational parameters such as $\mathrm{CO}_{2}$ mass flow rate and solution flow rate were fixed according to previous experience of the group (Sosa et al., 2011) at $0.7 \mathrm{~kg} / \mathrm{h}$ and $1 \mathrm{~mL} / \mathrm{min}$, respectively.

The rosemary extract used had a mean solid content of $(2.7 \pm 0.1) \% w t$. with a mean polyphenol content of $(110 \pm 30) \mathrm{mg}$ GAE/g solid. The mean rosmarinic and carnosic acid concentration was $(34 \pm 8) \mathrm{mg} / \mathrm{g}$ and $(58 \pm 15) \mathrm{mg} / \mathrm{g}$, respectively.

Results in terms of polyphenol, rosmarinic and carnosic acids content per mass of solids ( $\mathrm{C}_{\text {polyy }}$ $\left.\mathrm{C}_{\mathrm{ros}}, \mathrm{C}_{\mathrm{car}}\right)$ and global yield of solids $\left(\% \mathrm{\eta}_{\mathrm{G}}\right)$ are displayed in Table 1.

As shown in Table 1, the recovery of antioxidants is low; the maximum is achieved at $12 \mathrm{MPa}$ and $35 \stackrel{\circ}{\circ}$ with $13.3 \%$. Nevertheless, the concentration of antioxidant in the powder is, in general, increased with respect to the reference dried extract obtained by rotaevaporation; at $8 \mathrm{MPa}$ and 50 드, it is almost doubled.

Particle size of rosemary extract precipitates was analyzed by SEM micrographs (Figure 2). At all operating conditions, individual particles are below $1 \mu \mathrm{m}$ (Figure 2.a). However, they form agglomerates up to $200 \mu \mathrm{m}$ depending on the operating conditions. Increasing temperature at constant pressure decreases the size of agglomerates from $200 \mu \mathrm{m}$, at $25^{\circ} \mathrm{C}$ and $10 \mathrm{MPa}$ (Figure 2.b), to $50 \mu \mathrm{m}$, at $50^{\circ} \mathrm{C}$ and $10 \mathrm{MPa}$ (Figure 2.c). 

a small total amount of solids and individual particle size in the submicron range, the polyphenol content of the effluent was analyzed. Nevertheless the mass balance was not closed; there was a deficit of antioxidants of approximately $25 \%$. This deficit is likely due to the difficulties in the recovery of the precipitated powder from the vessel and filter devices. molar \% of ethanol as a co-solvent, close to the concentration achieved in the precipitation vessel, at $27.5 \mathrm{MPa}$ and $50^{\circ} \mathrm{C}$, is $0.018 \mathrm{mg} / \mathrm{g}$. It decreases with temperature and increases with pressure and cosolvent concentration. Extrapolating to operating conditions in the SAS experiments, it would imply a loss of carnosic acid between 5 to 10 wt.\%. Another plausible reason for the low yield achieved is the loss of individual particles through the filters due to its small particle size, as shown in Figure 2, hence only agglomerates could be retained. Additionally, the kinetics of the precipitation of rosemary antioxidants could be too slow and take place mainly outside of the precipitator. parameters were changed: concentration of the solution and diameter of the nozzle. The concentration of the solution was increased by partially evaporating the ethanol from the extract at vacuum. The nozzle diameter was adapted by connecting a stainless steel tube of $7 \mathrm{~mm}$ length and Table 2.

Concentration of initial solution seems to play a major role increasing the global yield of precipitation up to $90 \%$. The increase in the initial concentration of the solution leads to a faster supersaturation, in agreement with the possible reasons for the low yield of the process. However, a purification of the extract (e.g. higher concentration of polyphenols, rosmaric and carnosic acid in the SAS powder with respect to the powder obtained by vacuum evaporation) is not achieved. 

operating conditions are inside the two-phase region of the system: solute-solvent-antisolvent. The effect of reduction in the one phase region is the decrease in particle size. In principle, the solute is considered not to have a significant effect on this system, so only the solvent-antisolvent (ethanol $\mathrm{CO}_{2}$ ) phase diagram is taken into account. According to this diagram (Chiu et al., 2008), the experiments at $40^{\circ} \mathrm{C}$ and $10 \mathrm{MPa}$ are carried out in the 1 phase region and those at $50^{\circ} \mathrm{C}$ and $10 \mathrm{MPa}$ are at the boundary of the two phase region. However, there is a significant increase in global yield when using the $0.130 \mathrm{~mm}$ diameter nozzle at $40^{\circ} \mathrm{C}$ and $10 \mathrm{MPa}$, whereas there is no noteworthy change at $50^{\circ} \mathrm{C}$ and $10 \mathrm{MPa}$. There is no clear reason for this observation; it is probably related to aforementioned mechanical limitations in the recovery of the particles due to the small amount processed.

\subsection{Co-precipitation}

The solutions of polymer in pure ethanol (96\%) were processed at the most favorable operating conditions for the precipitation of the extract $\left(50^{\circ} \mathrm{C}\right.$ and $\left.10 \mathrm{MPa}\right)$. However, no particles were obtained even when it was processed with rosemary ethanolic extracts; similar findings were reported in literature: Poloxamer 407 processed from dichloromethane solutions or Poloxamer 188 from solutions of ethanol/ chloroform, were only successfully precipitated at $8 \mathrm{MPa}$ and $35^{\circ} \mathrm{C}$ when drug crystals acted as seed and thus providing heteronuclei for the precipitation of polymer (Majerik et al., 2007). In this case, pressure was increased in order to get a faster precipitation of the rosemary extracts. The extracts were successfully co-precipitated with both poloxamers at $14 \mathrm{MPa}$ and $50^{\circ} \mathrm{C}$. The rosemary extracts used in these experiments had a mean solid content of ( $3.7 \pm 0.1) \% w t$. with a mean polyphenol content of $91 \mathrm{mg} \mathrm{GAE} / \mathrm{g}$ solid; hence the polymer concentration in the solution was also the concentration of pluronics used in previous experiments to precipitate the pure polymer. 
Also, precipitation of extract alone was performed at the same operating conditions to verify the recovery of carnosic and rosmarinic acid, $46 \%$ wt and $13 \%$, respectively. The global yield of solids was $48 \%$ with a mean polyphenol content of $91 \mathrm{mg} \mathrm{GAE} / \mathrm{g}$ solid.

From DSC analysis (Figure 3), the co-precipitation of the extract and the polymer can be verified. After SAS processing the melting temperature of the polymer is decreased from $57.6^{\circ} \mathrm{C}$ to $52.0^{\circ} \mathrm{C}$, and also the melting peak is broader indicating that the processed polymer is less crystalline. The presence of the rosemary extract in the co-precipitated product is evidenced by the negative slope of its base line with respect to the unprocessed polymer, due to the superposition of the extract profile on the flat base line of the unprocessed polymer.

The loading of the polymer particles with the extract was determined through polyphenol content by Folin-Cicocalteu method resulting in $30 \mathrm{mg} \mathrm{GAE} / \mathrm{g}$ in F127 and $23 \mathrm{mg} \mathrm{GAE} / \mathrm{g}$ in F88 (the mean standard deviation was $10 \%)$. This means a ca. $100 \%$ encapsulation efficiency $(110 \%$ and $90 \%$, respectively) taking into account that the polyphenol content in the precipitation of the extract alone at the same operating conditions was $91 \mathrm{mg} \mathrm{GAE} / \mathrm{g}$ and supposing a similar global precipitation efficiency of the polymer and the extract. Consequently, the encapsulation process avoids the loss of antioxidants that was observed during the precipitation experiments of pure extract.

Particle size rosemary extracts encapsulated in Pluronic was also below $1 \mu \mathrm{m}$ according to SEM micrographs (Figure 2.d); moreover, the size of the agglomerates was reduced to values between $5-20 \mu \mathrm{m}$, due to the increase in pressure (14 MPa) and the presence of the polymer. Only the product obtained with Pluronic F127 is shown as it looked similar with both polymers. Additionally, the polyphenol release from polymer co-precipitates was measured and compared to the profile from the pure extract SAS product and physical mixtures thereof with both polymers (Figure 4). It is shown that all polyphenols (F88: 100\%; F127: 88\%) are released from the coformulations in the first hour, whereas only the $15 \%$ of the polyphenols are released from the pure extract product. The decrease of the amount of dissolved polyphenols with time in polymer formulations, $20 \%$ in both cases, can be due to degradation by the oxygen content in the phosphate 
buffer and to light. The improvement in the dissolution rate of the polyphenols is not only due to the effect as surfactant of both polymers, but to the co-precipitation process as physical mixtures of the processed extract and the polymers dissolved to a lower extent (F88: 60\%; F127: 75\%). Moreover, the degradation of polyphenols during the experiments was significantly higher in the physical mixtures; above $50 \%$ for both polymers.

\section{Conclusions}

Supercritical antisolvent process shows to be promising for the encapsulation of rosemary ethanolic extract with poloxamers to obtain a readily aqueous soluble powder; as shown by the polyphenol release profile, ca.100\% of the polyphenols are dissolved in a phosphate buffered aqueous solution $(\mathrm{pH}=6.8$ ) after one hour from the encapsulated product, while ca.65 \% of the antioxidants are dissolved from the pure extract precipitate using the polymers as surfactants and only ca. $3 \%$ of the polyphenols from the pure extract precipitate are solubilized. Besides, the protection against degradation factors during the dissolution is higher in the co-precipitated product. The obtained particles are in the submicron range, as well as the pure precipitated particles, although they build up agglomerates between 5 to $20 \mu \mathrm{m}$.

This encapsulation process seems to be promising concerning its coupling with supercritical fluid techniques to enrich ethanolic extracts, such as the supercritical antisolvent fractionation process developed by Visentin and co-workers (2011).

\section{Acknowledgments}

The authors thank the financial support of Junta de Castilla y Leon (Spain) through the project GR11/2008. A. Visentin acknowledges the Erasmus Mundus program from the European Comission. S.Rodríguez-Rojo thanks the Spanish Ministry of Education for her postdoctoral grant.

(1) 


\section{References}

Bailey, D.T., Richheimer, S.L., Bank, V.R., \& King, V.T. (1999). High purity carnosic acid from rosemary and sage extracts by $\mathrm{pH}$-controlled precipitation - US Patent 5,859,293.

Cháfer, A., Fornari, T., Berna, A., Ibañez, E., \& Reglero, G. (2005). Solubility of solid carnosic acid in supercritical $\mathrm{CO}_{2}$ with ethanol as a co-solvent. Journal of Supercritical Fluids, 34, 323-329.

Chiu, H-Y., Lee, M-J., \& Lin, H-M. (2008). Vapor -Liquid Phase Boundaries of Binary Mixtures of Carbon Dioxide with Ethanol and Acetone. Journal of Chemical and Engineering Data, 53, $2393-2402$.

Cocero, M.J., Martín, A., Mattea, F., \& Varona, S. (2009). Encapsulation and co-precipitation processes with supercritical fluids: Fundamentals and applications. Journal of Supercritical Fluids, 47, 546-555.

Mattea, F., Martín, A., Cocero, M.J. (2009). Carotenoid processing with supercritical fluids. Journal of Food Engineering 93, 255-265

Cuvelier, M-E., Richard, H., \& Berset, C. (1996). Antioxidative Activity and Phenolic Composition of Pilot-Plant and Commercial Extracts of Sage and Rosemary. Journal of the American Oil Chemists' Society, 73(5), 645-652.

Decker, E. A. (1998). Strategies for manipulating the prooxidative/antioxidative balance of foods to maximize oxidative stability. Trends in Food Science \& Technology, 9 (6), 241-248.

Escobar-Chávez, J. J., López-Cervantes, M., Naïk, A., Kalia, Y. N., Quintanar-Guerrero, D., \& GanemQuintanar, A. (2006). Applications of thermoreversible Pluronic F-127 gels in pharmaceutical formulations. Journal of Pharmacy \& Pharmaceutical Science, 9 (3), 339-358.

Etter, S.C. (2005). Rosmarinus officinalis as an Antioxidant. Journal of Herbs, Spices and Medicinal Plants, 11 (1), $121-159$.

Kosaraju, S. L., Labbett, D., Emin, M., Konczak, I., \& Lundin, L. (2008). Delivering polyphenols for healthy ageing. Nutrition \& Dietetics, 65 (3), S48-S52. 
Majerik, V., Charbit, G., Badens, E., Horváth, G., Szokonya, L., Bosc, N., \& Teillaud, E. (2007). Bioavailability enhancement of an active substance by supercritical antisolvent precipitation, Journal of Supercritical Fluids, 40, 101-110.

Meterc, D., Cocero, M.J., \& Weidner, E. (2009). Comparing PGSS and GAS process for drying of green tea extracts. Proceedings of the 9th International Symposium on Supercritical Fluids, Archachon (France).

Navarrete, A., Herrero, M., Martín, A., Cocero, M.J., \& Ibáñez, E. (2011). Valorization of solid wastes from essential oil industry. Journal of Food Engineering, 104, 196-201.

Ratnam, D. V., Ankola, D.D., Bhardwaj, V., Sahana, D.K., \& Kumar, M.N.V.R. (2006). Role of antioxidants in prophylaxis and therapy: A pharmaceutical perspective. Journal of Controlled Release, 113, 189-207.

Rodríguez-Meizoso, I., Quan, C., Mendiola, J.A., Cifuentes, A., Turner, C., \& Ibáñez, E. (2008). Particle formation by Supercritical Fluid technology as drying processes for antioxidant extracts. Proceedings of the $11^{\text {th }}$ European Meeting on Supercritical Fluids, Barcelona, Spain.

S. Rodríguez-Rojo, A. Visentin, D. Maestri, M. J. Cocero, Assisted extraction of rosemary antioxidants with green solvents, Submitted to Journal of Food Engineering, May 2011.

Singleton, V. L., Orthofer, R., \& Lamuela-Raventos, R. M. (1999). Analysis of total phenols and other oxidation substrates and antioxidants by means of Folin-Ciocalteu Reagent. Methods in Enzymology, 299, 152-178.

Soler-Rivas, C., Marín, F.R., Santoyo, S., García-Risco, M.R., Señoráns, F.J., \& Reglero, G. (2010). Testing and enhancing the in vitro bioaccessibility and bioavailability of Rosmarinus officinalis extracts with a high level of antioxidant abietanes. Journal of Agricultural and Food Chemistry, 58(2), 1144-52.

Sosa, M.V., Rodríguez-Rojo, S., Mattea, F., Cismondi, M., \& Cocero, M.J. (2011). Green tea encapsulation by means of high pressure antisolvent coprecipitation. Journal of Supercritical Fluids, 56, 304-311. 
Souza, C. R. F., Schiavetto, I. A., Thomazini, F. C. F., \& Oliveira, W. P. (2008). Processing of Rosmarinus Officinalis L. extract on spray and spouted bed dryers, Brazilian Journal of Chemical Engineering, 25, 59-69.

Sharma, P. K., Reilly, M. J., Jones, D. N., Robinson, P. M., \& Bhatia, S. R. (2008). The effect of pharmaceuticals on the nanoscale structure of PEO-PPO-PEO micelles. Colloid and Surfaces B: Biointerfaces, 61 (1), 53-60.

Visentín, A., Cismondi, M., \& Maestri, D. (2011). Supercritical CO2 fractionation of rosemary ethanolic oleoresins as a method to improve carnosic acid recovery. Innovative Food Science and Emerging Technologies, doi:10.1016/j.ifset.2011.01.004

Wellwood, C. R. L., \& Cole, R. A., (2004). Relevance of Carnosic Acid Concentrations to the Selection of Rosemary, Rosmarinus officinalis (L.), Accessions for Optimization of Antioxidant Yield. Journal of Agricultural and Food Chemistry, 52 (20), 6101-6107. 


\section{Figure captions list}

Figure 1. Schematic diagram of the SAS pilot plant.

Figure 2: SEM. a) SAS precipitate with F-127 at $14 \mathrm{MPa}$ and $50^{\circ} \mathrm{C}$ b) SAS precipitate at $10 \mathrm{MPa}$ and $35^{\circ} \mathrm{C}$ c) SAS precipitate at $10 \mathrm{MPa}$ and $50^{\circ} \mathrm{C}$ d) SAS co-precipitate with $\mathrm{F}-127$ at $14 \mathrm{MPa}$ and $50^{\circ} \mathrm{C}$ Figure 3. DSC analysis: - SAS co-precipitation of extract and Pluronic ${ }^{\circledR} \mathrm{F} 127$ at $14 \mathrm{MPa}$ and $40^{\circ} \mathrm{C} .-$ unprocessed Pluronic ${ }^{\circledR} \mathrm{F} 127$; --- SAS precipitation of extract at $14 \mathrm{MPa}$ and $40^{\circ} \mathrm{C}$. Figure 4: Polyphenols release profiles from different co-formulations ( $\bullet$ F127 and $\backsim P 88$ ), pure precipitated rosemary extract $(\triangle)$ at the same operating conditions $\left(14 \mathrm{MPa}\right.$ and $\left.50^{\circ} \mathrm{C}\right)$, and physical mixtures thereof $(\diamond \mathrm{F} 127-\mathrm{SAS}$ and $\square \mathrm{P} 88-\mathrm{SAS})$. 


\section{Figures}

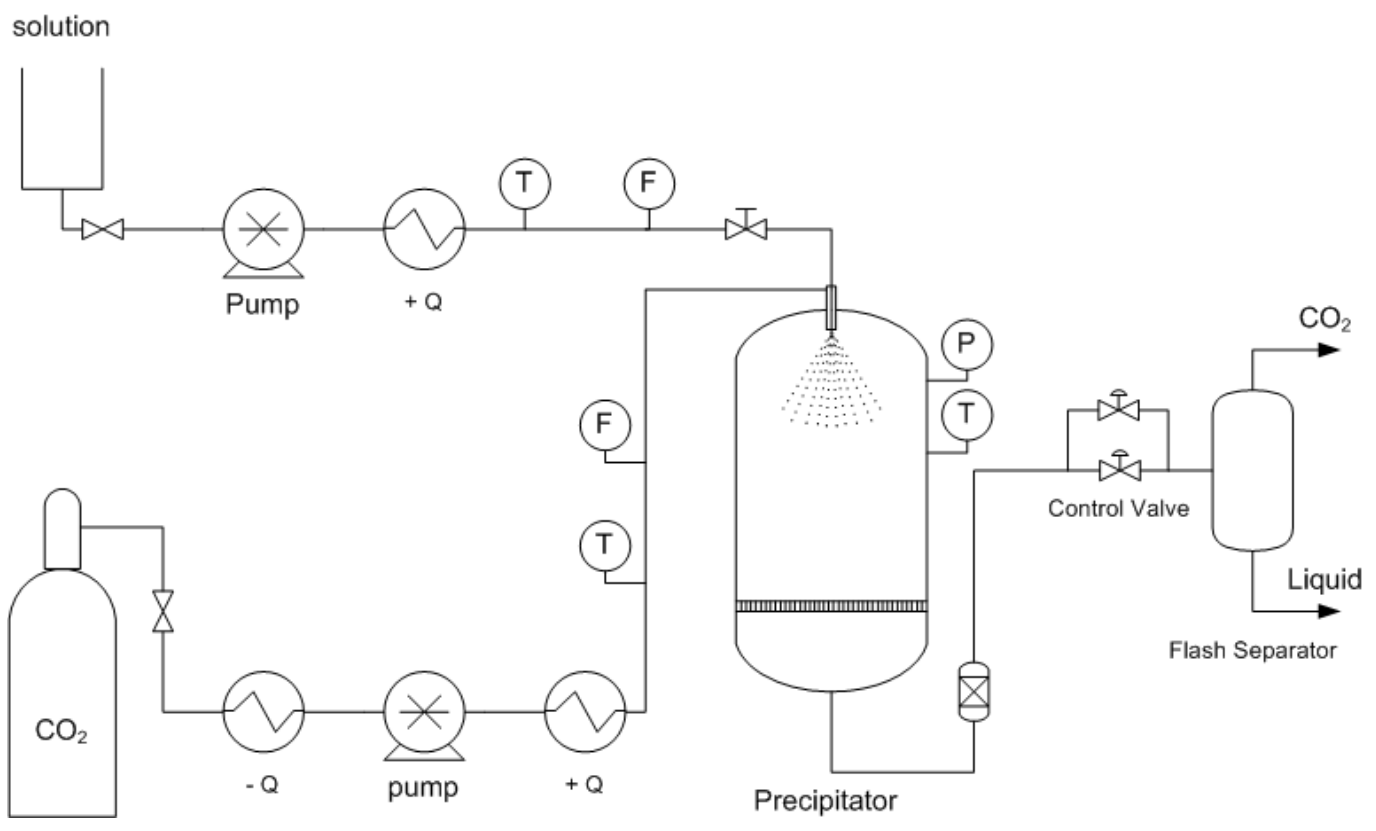

Figure 1. Schematic diagram of the SAS pilot plant. 

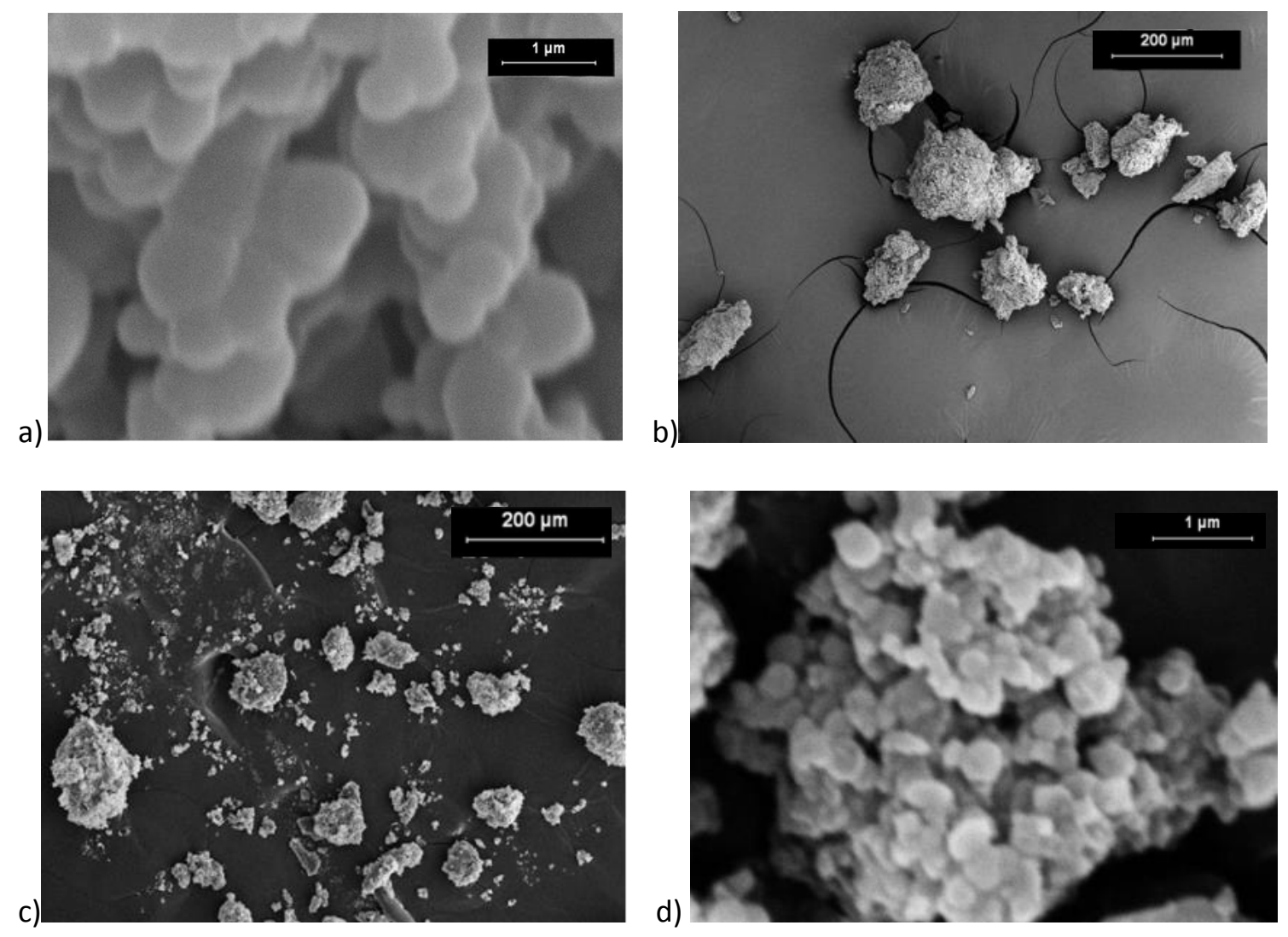

Figure 2: SEM. a) SAS precipitate with F-127 at $14 \mathrm{MPa}$ and $50^{\circ} \mathrm{C}$ b) SAS precipitate at $10 \mathrm{MPa}$ and $35^{\circ} \mathrm{C}$ c) SAS precipitate at $10 \mathrm{MPa}$ and $50^{\circ} \mathrm{C}$ d) SAS co-precipitate with $\mathrm{F}-127$ at $14 \mathrm{MPa}$ and $50^{\circ} \mathrm{C}$ 


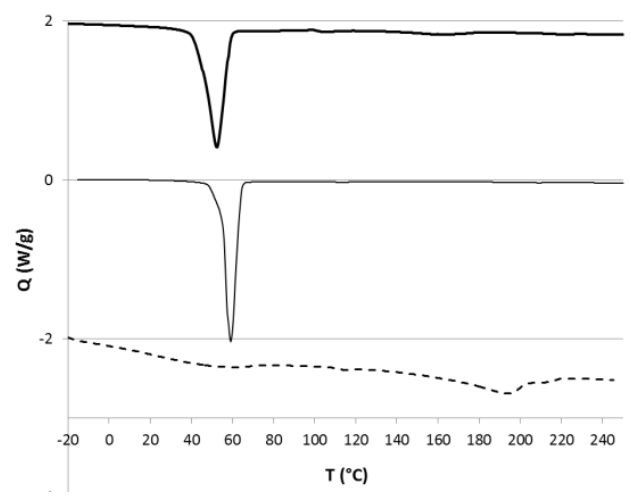

Figure 3. DSC analysis: - SAS co-precipitation of extract and Pluronic ${ }^{\circledR} \mathrm{F} 127$ at $14 \mathrm{MPa}$ and $40^{\circ} \mathrm{C}$. unprocessed Pluronic ${ }^{\circledR} \mathrm{F} 127$; --- SAS precipitation of extract at $14 \mathrm{MPa}$ and $40^{\circ} \mathrm{C}$. 


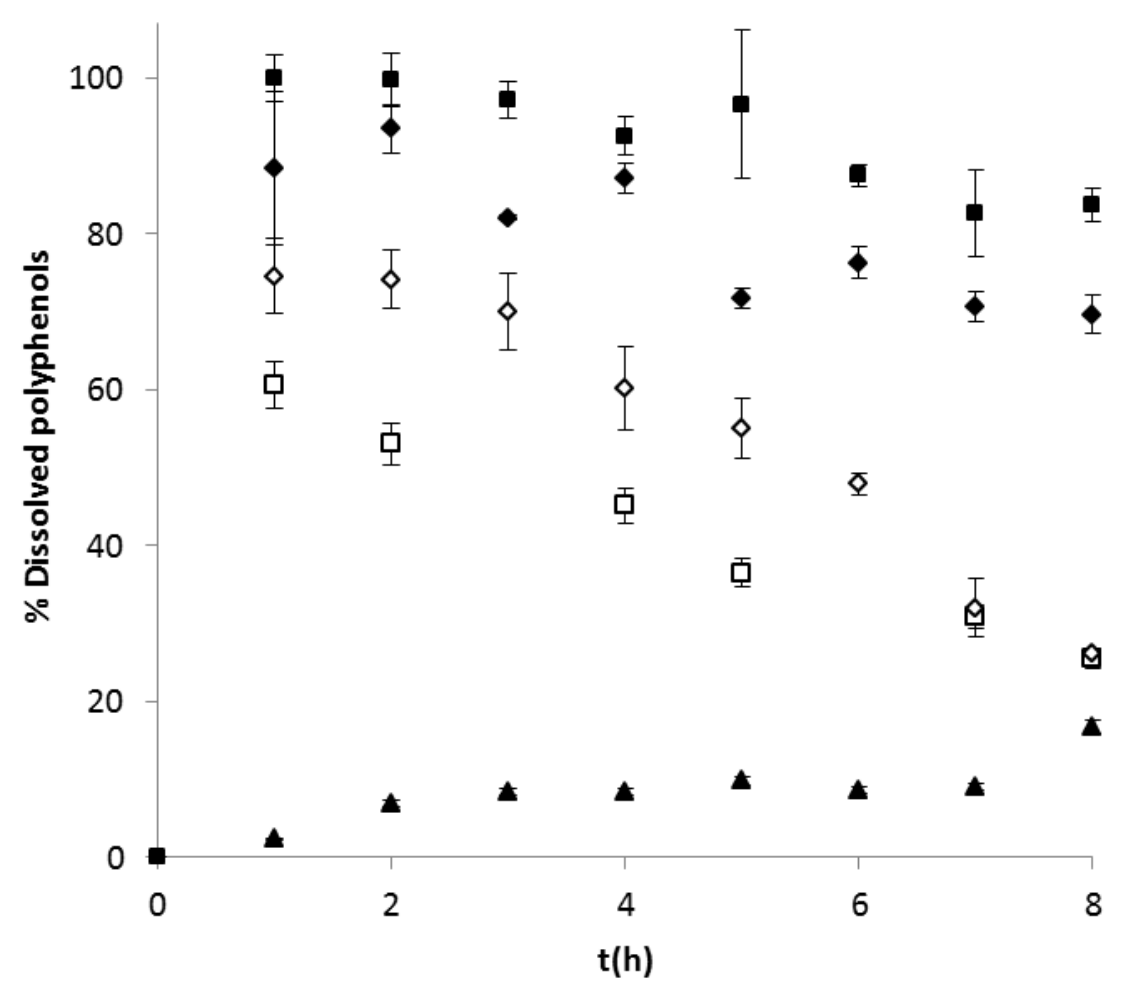

Figure 4: Polyphenols release profiles from different co-formulations ( $\bullet 127$ and $\bullet P 88$ ), pure precipitated rosemary extract $(\Delta)$ at the same operating conditions $\left(14 \mathrm{MPa}\right.$ and $\left.50^{\circ} \mathrm{C}\right)$, and physical mixtures thereof $(\diamond \mathrm{F} 127-$ SAS and $\square \mathrm{P} 88-\mathrm{SAS})$. 
Tables

Table 1. Effect of temperature and pressure on the polyphenolic content and yield of the SAS precipitatated rosemary extracts

\begin{tabular}{|l|l|l|r|r|l|}
\hline $\begin{array}{l}\mathrm{T} \\
\left({ }^{\circ} \mathrm{C}\right)\end{array}$ & $\begin{array}{l}\mathrm{P} \\
(\mathrm{MPa})\end{array}$ & $\begin{array}{l}\mathrm{C}_{\text {poly }} \\
(\mathrm{mg} \mathrm{GAE} / \mathrm{g})\end{array}$ & $\begin{array}{l}\mathrm{C}_{\text {ros }} \\
(\mathrm{mg} / \mathrm{g})\end{array}$ & $\begin{array}{l}\mathrm{C}_{\text {car }} \\
(\mathrm{mg} / \mathrm{g})\end{array}$ & $\% \mathrm{\eta}_{\mathrm{G}}$ \\
\hline \multirow{5}{*}{25} & 8 & $120 \pm 30$ & 71 & 18 & 7.3 \\
\cline { 2 - 6 } & 10 & $140 \pm 50$ & 65 & 21 & 6.9 \\
\cline { 2 - 6 } & 12 & 90 & $*$ & $*$ & 0.8 \\
\hline 35 & 8 & $90 \pm 5$ & 32 & 101 & 5.2 \\
\cline { 2 - 6 } & 10 & $80 \pm 20$ & 35 & 35 & 8.8 \\
\cline { 2 - 6 } & 12 & $60 \pm 20$ & 27 & 30 & 14.8 \\
\hline 40 & 8 & 30 & $*$ & $*$ & 1.0 \\
\cline { 2 - 6 } & 10 & $110 \pm 18$ & 44 & 37 & 5.4 \\
\cline { 2 - 6 } & 12 & $90 \pm 8$ & 13 & 32 & 2.4 \\
\hline 50 & 8 & $230 \pm 30$ & 6.7 & 69 & 0.3 \\
\cline { 2 - 6 } & 10 & $76 \pm 17$ & 44 & 77 & 17.9 \\
\cline { 2 - 6 } & 12 & $140 \pm 30$ & 46 & 47 & 1.2 \\
\hline
\end{tabular}

* The amount of sample was not enough for the analysis 
Table 2. Effect of nozzle diameter and solids concentration on the polyphenolic content and yield of the SAS precipitatated rosemary extracts

\begin{tabular}{|c|c|c|c|c|c|c|c|}
\hline $\begin{array}{l}\mathrm{T} \\
\left({ }^{\circ} \mathrm{C}\right)\end{array}$ & $\begin{array}{l}\mathrm{P} \\
\text { (MPa) }\end{array}$ & $\begin{array}{l}\text { Nozzle } \\
(\mathrm{mm})\end{array}$ & $\begin{array}{l}\text { C Solids, IN } \\
\text { (\%wt.) }\end{array}$ & $\begin{array}{l}\mathrm{C}_{\text {poly }} \\
\text { (mg GAE/g) }\end{array}$ & $\begin{array}{l}C_{\text {ros }} \\
(\mathrm{mg} / \mathrm{g})\end{array}$ & $\begin{array}{l}\mathrm{C}_{\mathrm{car}} \\
(\mathrm{mg} / \mathrm{g})\end{array}$ & $\% \eta_{G}$ \\
\hline \multirow[t]{2}{*}{35} & \multirow{2}{*}{12} & \multirow[t]{2}{*}{1} & 2.7 & $60 \pm 20$ & 27 & 30 & 14.8 \\
\hline & & & 4.6 & $32 \pm 8$ & 4 & 73 & 19.0 \\
\hline \multirow[t]{4}{*}{40} & \multirow[t]{4}{*}{10} & \multirow[t]{3}{*}{1} & 2.7 & $110 \pm 18$ & 13 & 32 & 5.4 \\
\hline & & & 4.6 & $58 \pm 9$ & 20 & 111 & 28.0 \\
\hline & & & 7.4 & $39 \pm 8$ & 10 & 83 & 90.0 \\
\hline & & 0.130 & 3.5 & $67 \pm 12$ & 9 & 102 & 52 \\
\hline \multirow[t]{3}{*}{50} & \multirow[t]{3}{*}{10} & \multirow[t]{2}{*}{1} & 2.7 & $76 \pm 17$ & 44 & 77 & 17.9 \\
\hline & & & 3.5 & $82 \pm 16$ & 74 & 181 & 57.5 \\
\hline & & 0.130 & 3.8 & $81 \pm 17$ & 53 & 161 & 50.0 \\
\hline
\end{tabular}

